\title{
AUDIT SISTEM INFORMASI AKADEMIK MENGGUNAKAN FRAMEWORK COBIT 4.1 (STUDI KASUS UNIVERSITAS ARS BANDUNG)
}

\author{
Riswan Hadiyanto1 ${ }^{1}$, Muhammad Diki2², Fira Fathonah3 ${ }^{3}$, El Miana Assni4 ${ }^{4}$, Aji Nugroho5 ${ }^{5}$, Robby \\ Kurnia6 $^{6}$, Muhammad Farhan7 ${ }^{7}$, Agi Aghniyasari8 8 \\ ${ }^{1,2}$ Sistem Informasi, Fakultas Teknik, Universitas ARS Bandung \\ ${ }^{1}$ riswanhadi@gmail.com, ${ }^{2}$ mdiki@gmail.com, ${ }^{3}$ firafatonah18@gmail.com, ${ }^{4}$ elmiana@gmail.com, \\ 5ajinugroho@gmail.com, ${ }^{6}$ robbykurnia@gmail.com, ${ }^{7}$ mfarhan@gmail.com, ${ }^{8}$ agiaghniyasari@gmail.com
}

\begin{abstract}
Abstrak
Teknologi informasi dan sistem informasi memiliki peranan yang begitu penting bagi suatu instansi atau perusahaan yang memanfaatkan teknologi informasi pada kegiatan bisnis. Universitas ARS adalah salah satu perguruan tinggi yang menggunakan aplikasi atau sistem informasi sebagai pengelola layanan administrasi dan strategi bisnis. SIAKAD(Sistem administrasi akademik) adalah salah satu sistem informasi akademik yang dibangun untuk memberikan kemudahan kepada pengguna dan instansi dalam kegiatan administrasi akademik secara online, seperti pembuatan jadwal kuliah, pengisian KRS online mahasiswa dan proses administrasi mahasiswa.Pengelolaan Sistem Informasi Akademik yang tidak dikelola dengan baik akan berdampak pada rendahnya kepuasan pengguna/mahasiswa dan rendahnya kualitas layanan, sehingga dapat mempengaruhi tingkat stakeholder terhadap institusi. Hal tersebut dapat diatasi dengan pemantauan/evaluasi secara periodik terhadap pelaksanaaan SIAKAD. Penelitian akan dilakukan evaluasi pengelolaan penggunaan sistem informasi akademik yang tidak terkelola dengan baik. Dengan adanya pemantauan terhadap proses pelaksanaan SIAKAD diharapkan dapat memperbaiki segala kekurangan dan kelemahan sistem yang sedang berjalan. Dalam penelitian Metode Penelitian yang digunakan adalah tahapan Perencanaan(planning), Pemeriksaan lapangan(Fied Work), Pelaporan(Reporting), Tindak lanjutan (Follow Up)dan dengan menggunakan Tool Frame Work COBIT(Control Objectives For Information and Related Technologi)Versi 4.1yang dikeluarkan oleh ISACA(Information System Audit Control Assosiation). Dengan berdasarkan hasil perhitungan setiap proses TI yang terdapat domain Planning and Organization(PO) dan Delivery and Support(DS).
\end{abstract}

Kata kunci : sistem informasi, cobit, audit

\section{Pendahuluan}

Penerapan TI (Teknlogi Informasi) saat ini semakin berkembang mengikuti perkembangan tekologi yang ada, hampir semua aspek kegiatan manusia dipengaruhi oleh TI (Teknologi Informasi) tak luput juga dalam dunia bisnis saat ini seperti pemerintahan, sektor industri, sektor swasta dan dunia pendidikan. TI dipercaya dapat membantu meningkatkan efisiensi dan efektifitas proses-proses bisnis organisasi dalam mencapai tujuan, TI yang semakin canggih dan modern mendorong kemajuan dan perkembangan otomasi dan digitalisasi dibidang informasi.

Universitas ARS Bandung merupakan perguruan tinggi swasta yang telah menerapkan dan memanfaatkan teknologi informasi dalam proses operasionalnya, seperti sistem informasi akademik. SIAKAD (Sistem Informasi Akademik) merupakan aplikasi yang digunakan untuk mengolah data yang terkait dengan kegiatan akademik. Sebagai perguruan tinggi yang memberikan jasa pendidikan, maka SIAKAD ( Sistem Informasi Akademik) memiliki fungsi yang cukup penting dan salah satu pendukung dari pencapaian sasaran bisnis. SIAKAD Universitas ARS Bandung terdiri dari penjadwalan, pengisian KRS, pengelolaan administrasi perkuliahan, nilai mahasiswa, presentase mahasiswa, dan lain sebagainya.

Pengolahan SIAKAD Sistem Informasi Akademik yang tidak terkelola dengan baik dapat memicu munculnya permasalan yang akan berdampak pada rendahnya kualitas layanan, rendahnya tingkat kepuasan mahasiswa/pengguna dapat mempengaruhi tingkat kepercayaan stakeholder dan SIAKAD (Sistem Infrormasi Akademik). Universitas ARS Bandung juga lambat dalam memberikan layanan infromasi sehingga infromasi yang dibutuhkan tidak didapatkan oleh pengguna. Dengan demikian sangat diperlukan untuk memantau pelaksanaan SIAKAD yang sedang berjalan untuk memastikan bahwa pelaksanaan tersebut telah mendukung tujuan bisnis institute. Hal tersebut dapat diatasi dengan pemantauan/evaluasi secara periodik terhadap pelaksanaan SIAKAD. 
Salah satu tool yang dapat digunakan adalah framework COBIT

COBIT (Control Objectives for Information and Related Technology) standar kerangka kerja baku internasioanl yang digunakan untuk melakukan audit tingkat kematangan tatakelola proses-proses penyelenggaraan dalam pengelolaan TI, kerangka kerja COBIT dibangun dari visi misi dan kebijakan institusi. Hasil analisis tingkat kematangan kondisi saat ini terhadap keseimbangan antara tujuan yang akan dicapai dari implementasi TI terhadap kebijakan yang diimplementasikan oleh pihak penyelenggara.

Dalam kerja COBIT bukan hanya dapat memberikan evaluasi terhada keadaan tata kelola Teknologi Informasi, mengetahui tingkat kematangan TI tetapi juga dapat memberikan masukan yang digunakan untuk perbaikan pengelolaannya di masa mendatang. Pada penelitian ini difokuskan pada domain PO (Plan and Organize) dan DS (Deliver and Support).

\subsection{Tata Kelola TI dan Sistem Informasi Akademik}

\subsubsection{Pengertian Tata Kelola Teknologi Informasi}

Tata Kelola TI merupakan suatu bentuk komitmen, kesadaran dan proses pengendalian manajemen organisasi terhadap sumber daya TI mencakup mulai dari sumber daya komputer (software, brainware, database dan sebagainya) hingga ke Teknologi Informasi dan Jaringan LAN/Internet. Maka dapat disimpulkan bahwa tujuan dibangunnya Tata kelola TI pada dasarnya untuk menyelaraskan sumberdaya TI dengan tujuan dan strategi organisasi serta dapat berfungsi sebagai enabler. (Admin, 2019)

\subsubsection{Sistem Informasi Akademik}

Sistem informasi akademik merupakan sebuah sistem yang digunakan oleh institusi pendidikan yang dimanfaatkan untuk meningkatkan pelayanan kepada mahasiswanya. Sistem infomasi akademik mempunyai banyak sekali manfaat bagi institusi dalam bidang pendidikan, baik itu dalam pengolahan data pengajaran, data nilai, dan data-data lainnya yang terkait dengan akademik pembelajaran dalam hal ini khususnya perguruan tinggi (Prihandoyo, 2018).

\subsection{Tujuan Audit}

Pada tahap ini peneliti harus menentukan bidang apa saja yang akan diakukukan audit. Audit system informasi pada Universitas ARS Bandung dengan fokus pada proses pelayanan.

\subsection{Tahapan Audit}

Menurut Ron Weber (1999) seperti dikutip oleh (Sulaeman, 2015) dalam bukunya yang berjudul Information System Control and Audit, menjelaskan 5 tahapan audit sistem informasi, yaitu :

1. Perencanaan audit (Planning The Audits) Perencanaan merupakan tahapan pertama pertama dalam audit. Tahapan ini dapat berisi aktivitas- aktivitas yang berbeda bagi auditor internal dan eksternal.

2. Pengujian Kendali (Test Of Controls) Pengujian kendali dilakukan apabila pada saat penilaian resiko kendali diperoleh hasil dibawah tingkat maksimum. Tujuan dari pengujian kendali adalah mengevaluasi dan memastikan kendali tersebut benar-benar reliable.

3. Pengujian Transaksi (Test Of Transactions) Pengujian transaksi untuk mengevaluasi apakah kekeliruan atau proses yang tidak menentu dari suatu transaksi telah membawa pokok pernyataan yang salah dari informasi finansial. Ciri pembuktian pengujian transaksi meliputi terjemahan catatan jurnal untuk sumber dokumen, pengujian file-file harga, dan menguji keakuratan perhitungan.

4. Pengujian Keseimbangan atau Keseluruhan Hasil (Test Of Balances Or Overral Results) Pengujian keseimbangan atau keseluruhan hasil dalam mengadakan cukup bukti / fakta untuk membuat suatu keputusan final dari kehilangan atau pernyataan yang salah yang terjadi ketika fungsi sistem informasi gagal dalam menyelamatkan aset, pemeliharaan integritas data, dan sistem yang efektif dan efisien.

5. Penyelesaian Audit (Completions Of The Audits) Penyelesaian merupakan tahapan terakhir dalam audit. Tahap ini berisi penyelesaian keseluruhan audit yang telah dilakukan agar didapatkan hasil yang sesuai dengan yang diharapkan.

\subsection{COBIT}

\subsubsection{Struktur COBIT}

Pada dasarnya struktur COBIT terdiri dari ringkasan eksekutif (executive summary), kerangka kerja (framework) berorientasi bisnis yang mencakup seluruh aktifitas TI, pedoman manajemen (management guidelines), sasaran pengendalian rinci (detailed control objectives), pedoman audit (audit guidelines), dan kumpulan alat implementasi (implementation tool set). (Suhartono, 2016) 


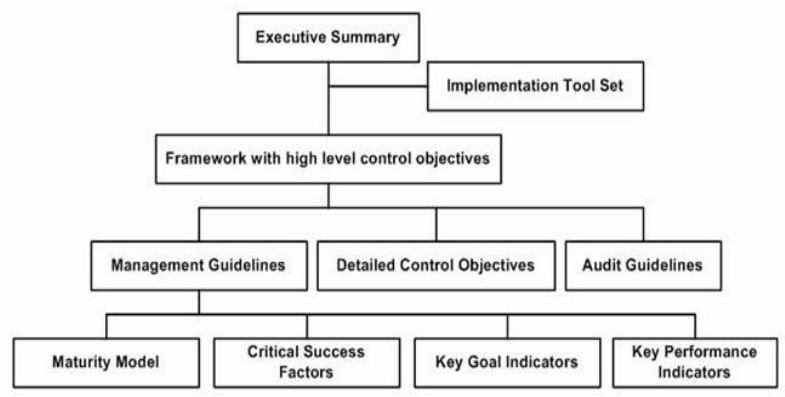

Gambar 1. Struktur COBIT

\subsubsection{Kerangka Kerja COBIT}

Kerja COBIT merupakan kumpulan praktekpraktek terbaik (best practices) dan bersifat generik, digunakan sebagai acuan dalam menentukan sasaran kendali (control objectives) dan proses-proses TI yang diperlukan dalam pengelolaan TI. Kerangka kerja COBIT terdiri dari 3 level control objectives dimulai dari level paling bawah yaitu activities. Activities merupakan kegiatan rutin yang memiliki konsep siklus hidup. Selanjutnya kumpulan activites dikelompokkan dalam proses TI (processes), kemudian proses-proses TI yang memiliki permasalahan yang sama dikelompokkan ke dalam domain (domains). (Suhartono, 2016)

\subsection{Teknik Pengelohan Data}

\subsubsection{Menentukan Jumlah Responden/ Sampel}

Pengertian sampel adalah bagian dari populasi yang didapatkan dengan menggunakan metode tertentu yang kemudian dianggap menjadi wakil dari populasi tersebut yang menjadi fokus dalam metode penelitian sosial atau penelitian statistika. (jagad, 2019).

$$
\text { Rumus : } s=\frac{\pi^{2} \cdot N \cdot P \cdot Q}{d^{2}(N-1)+\pi \cdot P \cdot Q}
$$

Keterangan

$\pi$ : dengan $\mathrm{dk}=1 \mathrm{1}$, taraf kesalahan bias $1 \%, 5 \%, 10 \%$

$\mathrm{P}=\mathrm{Q}=0,5$

$\mathrm{d}=0,05$

$\mathrm{s}=$ jumlah sampel

\subsubsection{Menentukan Sampel yang terpilih dari jumlah sampel terpilih}

Pada penelitian ini diperlukan pengambilan data melalui kuisioner yang akan disebarkan dan memerlukan responden yang akan diminta mengisi kuisioner tersebut sesuai pertanyaan yang akan diajukan terkait kasus yang diteliti berdasarkan standar COBIT versi 4.1. yang bertujuan untuk mendapatkan informasi secara tertulis dari responden mengenai tata kelola yang ada di Universitas ARS Bandung. Sebuah sampel dibutuhkan dalam penelitian dikarenakan tidak mungkin memeriksa semua populasi untuk diteliti karena keterbatasan waktu, tenaga dan biaya.

Pengambilan Sampel bermacam-macam tergantung jenis penelitian yang akan dilakukan. Secara garis besar, metode pengambilan sampel terdiri dari 2 kelas besar yaitu

- Probability Sampling (Random Sample)

- Non- Probability Sampling (Non-Random Sample).

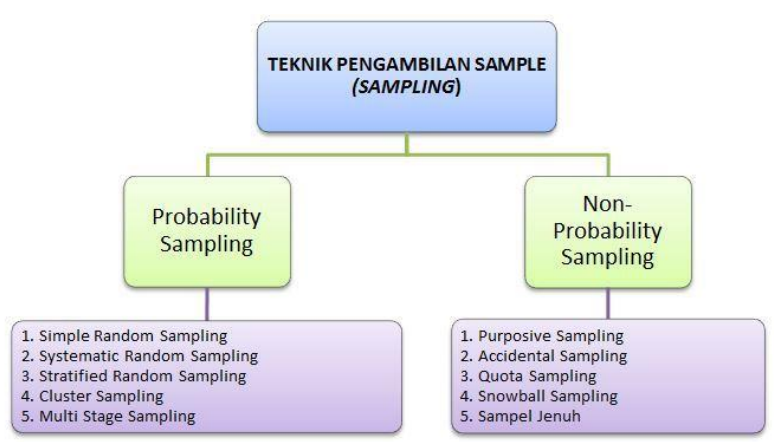

Gambar 2. Teknik Pengambilan Sampel

Dari jumlah sampel terpilih ditentukan sampel dengan teknik Penarikan Sampel secara Cluster (Cluster

Cluster Sampling adalah teknik sampling secara berkelompok. Pengambilan sampel jenis ini dilakukan berdasar kelompok / area tertentu. Tujuan metode Cluster Random Sampling antara lain untuk meneliti tentang suatu hal pada bagian-bagian yang berbeda di dalam suatu instansi. (salamadian, 2017)

Teknik sampling daerah ini sering digunakan melalui dua tahap yaitu :

- Menentukan sampel Jurusan dari populasi.

- Menentukan mahasiswa yang ada pada jurusan tersebut secara sampling.

Setelah sampel di cluster dilakukan pemilihan dengan teknik sampling purposive dengan pertimbangan sampel sumber datanya hanya pada mahasiswa yang pintar saja (IPK minimal 3,00).

\subsubsection{Teknik Analisa Data Statistik}

Teknik Analisis Data adalah suatu metode atau cara untuk mengolah sebuah data menjadi informasi sehingga karakteristik data tersebut menjadi mudah untuk dipahami dan juga bermanfaat untuk menemukan solusi permasalahan,

yang terutama adalah masalah yang tentang sebuah penelitian (Rizki, 2019).

Penelitian ini menggunakan teknik analisis data secara kuantitatif serta menggunakan teknik statistik deskriptif dengan hasil penyajian berupa tabel dan ukuran rata-rata kuisioner. 


\subsubsection{Instrumentasi}

Skala yang digunakan dalam penelitian ini adalah dengan mengacu skala pada maturity model yaitu skala $1-5$ berupa jawaban sangat tidak setuju (STS), tidak setuju (TS), netral (N), setuju (S) dan setuju sekali (SS). Penelitian yang akan dilakukan menggunakan instrument kuisioner yang mengacu pada COBIT versi 4.1, Domain PO dan DS digunakan karena, domain PO ini meliputi strategi dan taktik, serta identifikasi bagaimana TI dapat berkontribusi terhadap pencapaian sasaran bisnis, dan Domain DS ini mencakup penyampaian hasil aktual dari layanan yang diminta dukungan layanan terhadap pengguna serta pengelolaan data. Dengan ini domain yang akan digunakan adalah proses PO2, PO7, PO8 dan DS10, DS11.

\subsubsection{Indikator Kuisioner}

Sesuai metode COBIT pada proses PO2, PO7, PO8 dan DS10, DS11 memiliki aktivitas sebagai indikator yang akan diterapkan dalam kuisioner sebagai berikut :

PO 2 Mendefinisikan Arsitektur Informasi (Define the Information Architecture)

- PO2.1. Informasi Arsitektur Model

- PO2.2. Peraturan Kamus Data Perusahaan dan Data Perintah

- PO2.3. Pengelolaan Skema Klasifikasi Data

- PO2.4. Tingkat Keamanan

PO 7 Mengelola Sumber Daya Manusia (Manage Human Resources)

- PO7.2. Personil Kualifikasi

- PO7.3. Peran dan Tanggung Jawab

- PO7.7. Evaluasi Kinerja Kerja Karyawan

PO 8 Mengelola Kualitas (Manage Quality)

- PO8.1. Sistem manajemen Mutu

- PO8.2. Standar IT dan Praktik Kualitas

- PO8.3. Pengembangan dan akuisisi standar

- PO8.4. Fokus pada pelanggan

- PO8.5. Kegiatan yang berkelanjutan

- PO8.6. Pengukuran kualitas, pemantauan dan review

DS 10 Mengelola Permasalahan (Manage Problem)

- DS 10.1 Permintaan layanan dan kebutuhan informasi.

- DS 10.2 Kecenderungan pengawasan dan pelaporan.

DS 11 Mengelola Data (Manage Data)

- DS 11.1 Kebijakan dan prosedur yang ada untuk pengelolaan data yang didasarkan pada kebutuhan bisnis.

- DS 11.2 Pertukaran dan pengelolaan penyimpanan data

- DS 11.3 Peralatan dan keamanan pembuangan data yang tidak terpakai

- DS 11.4 Data yang mendukung dan restorasi yang teruji

\subsubsection{Deskripsi Sistem Informasi Akademik}

Manajemen Universitas ARS menyadari bahwa penggunaan teknologi informasi dalam mendukung system akademik sangat penting untuk meningkatkan system informasi akademik yang digunakan. System tata kelola yang tersedia di Universitas ARS pada umumnya sudah menggunakan Teknologi Informasi untuk mengolah data dan menghasilkan informasi yang berguna bagi setiap penggunanya. Adapun sumber daya yang perlu dikelola yaitu :

1. Infrastruktur Teknologi yang digunakan pada umumnya sudah mengikuti perkembangan teknologi saat ini, dan sangat membantu penggunanya dalam memperoleh informasi dan memudahkan kampus dalam pelayanan dan proses pembelajaran

2. Sistem Aplikasi Sistem aplikasi yang sudah digunakan pada umumnya sudah memiliki prosedur yang baku dalam penggunaanya. Namun masing-masing bagian kerja belum terintegrasi sepenuhnya, masih ada bagian yang belum terhubung ke system basis data yang digunakan

3. Informasi Data yang diperoleh belum scara maksimal diolah, hal ini berkaitan dengan belum terintegritasnya basis data yang digunakan sebagai server data.

\subsection{Penelitian Terdahulu}

Penelitian terkait dengan audit sistem informasi akademik menggunakan framework cobit 4.1 telah dilakukan oleh beberapa peneliti sebelumnya. Penelitian yang telah dilakukan sebelumnya digunakan sebagai penelitian pendukung dalam penelitian ini. Penelitian penelitian tersebut dirangkum dalam tabel berikut:

Tabel 1. Penelitian Terdahulu

\begin{tabular}{|c|c|c|c|}
\hline $\begin{array}{l}\text { Nama } \\
\text { Peneliti }\end{array}$ & Judul & Masalah & $\begin{array}{c}\text { Hasil } \\
\text { Penelitian }\end{array}$ \\
\hline $\begin{array}{l}\text { Neni } \\
\text { Purwati } \\
(2014)\end{array}$ & $\begin{array}{l}\text { AUDIT } \\
\text { SISTEM } \\
\text { INFOR } \\
\text { MASI } \\
\text { AKADE } \\
\text { MIK } \\
\text { MENGG } \\
\text { UNAKA } \\
\text { N } \\
\text { FRAME } \\
\text { WORK } \\
\text { COBIT } \\
4.1 \\
\text { (STUDI } \\
\text { KASUS } \\
\text { IBI }\end{array}$ & $\begin{array}{l}\text { Pengelolaan } \\
\text { Sistem } \\
\text { Informasi } \\
\text { Akademik } \\
\text { yang tidak } \\
\text { terkelola } \\
\text { dengan baik } \\
\text { akan } \\
\text { berdampak } \\
\text { pada } \\
\text { rendahnya } \\
\text { kualitas } \\
\text { layanan, } \\
\text { rendahnya } \\
\text { tingkat } \\
\text { kepuasan } \\
\text { pelanggan/ma }\end{array}$ & $\begin{array}{l}\text { Dari hasil } \\
\text { gap antar } \\
\text { tingkat } \\
\text { kematanga } \\
\text { n tata } \\
\text { kelola TI } \\
\text { saat ini } \\
\text { dengan } \\
\text { tingkat } \\
\text { kematanga } \\
\text { n yang } \\
\text { ingin } \\
\text { dicapai, } \\
\text { diketahui } \\
\text { pada } \\
\text { domain PO } \\
\text { dan DS }\end{array}$ \\
\hline
\end{tabular}




\begin{tabular}{|c|c|c|c|}
\hline $\begin{array}{c}\text { Nama } \\
\text { Peneliti }\end{array}$ & Judul & Masalah & $\begin{array}{c}\text { Hasil } \\
\text { Penelitian }\end{array}$ \\
\hline & $\begin{array}{l}\text { DARMA } \\
\text { JAYA) }\end{array}$ & $\begin{array}{l}\text { hasiswa, } \\
\text { sehingga } \\
\text { dapat } \\
\text { mempengaruh } \\
\text { i tingkat } \\
\text { kepercayaan } \\
\text { stakeholder } \\
\text { terhadap } \\
\text { institusi. }\end{array}$ & $\begin{array}{l}\text { prioritas } \\
\text { perbaikan } \\
\text { dilakukan } \\
\text { pada PO7 } \\
\text { (mengelola } \\
\text { sumber } \\
\text { daya } \\
\text { manusia } \\
\text { TI). }\end{array}$ \\
\hline $\begin{array}{l}\text { Kartika } \\
(2011)\end{array}$ & $\begin{array}{l}\text { PENGA } \\
\text { RUH } \\
\text { PENER } \\
\text { APAN } \\
\text { AUDIT } \\
\text { SISTEM } \\
\text { INFOR } \\
\text { MASI } \\
\text { TERHA } \\
\text { DAP } \\
\text { KINERJ } \\
\text { A } \\
\text { AUDIT } \\
\text { OR } \\
\text { DENGA } \\
\text { N } \\
\text { TEKNO } \\
\text { LOGI } \\
\text { INFOR } \\
\text { MASI } \\
\text { SEBAG } \\
\text { AI } \\
\text { VARIA } \\
\text { BEL } \\
\text { INTERV } \\
\text { ENING }\end{array}$ & $\begin{array}{l}\text { Menguji } \\
\text { pengaruh } \\
\text { penerapan } \\
\text { audit pada } \\
\text { sistem } \\
\text { informasi } \\
\text { pada kantor } \\
\text { akuntan } \\
\text { publik } \\
\text { terhadap } \\
\text { kinerja } \\
\text { auditor. }\end{array}$ & $\begin{array}{l}\text { Penerapan } \\
\text { audit } \\
\text { sistem } \\
\text { informasi } \\
\text { berpengaru } \\
\text { h secara } \\
\text { tidak } \\
\text { langsung } \\
\text { terhadap } \\
\text { kinerja } \\
\text { editor } \\
\text { melalui } \\
\text { teknologi } \\
\text { informasi } \\
\text { sebagai } \\
\text { variabel } \\
\text { interving }\end{array}$ \\
\hline $\begin{array}{l}\text { Pande } \\
\text { Putu } \\
\text { Gede } \\
\text { Putra } \\
\text { Pertama, } \\
\text { I Wayan } \\
\text { Ardiyasa } \\
\text { (2019) }\end{array}$ & $\begin{array}{l}\text { Audit } \\
\text { Keaman } \\
\text { an } \\
\text { Sistem } \\
\text { Informas } \\
\text { i } \\
\text { Perpusta } \\
\text { kaan } \\
\text { STMIK } \\
\text { STIKO } \\
\text { M Bali } \\
\text { Menggu } \\
\text { nakan } \\
\text { Kerangk } \\
\text { a Kerja } \\
\text { COBIT }\end{array}$ & $\begin{array}{l}\text { STMIK } \\
\text { STIKOM Bali } \\
\text { belum pernah } \\
\text { melakukan } \\
\text { audit } \\
\text { keamanan } \\
\text { terhadap } \\
\text { sistem } \\
\text { informasi } \\
\text { yang ada, } \\
\text { di mana } \\
\text { pernah } \\
\text { mengalami } \\
\text { kejadian } \\
\text { website tidak } \\
\text { bisa diakses } \\
\text { beberapa saat. } \\
\text { Untuk dapat } \\
\text { menghindari } \\
\text { kejadian yang } \\
\text { tidak } \\
\text { diinginkan }\end{array}$ & $\begin{array}{l}\text { Maturity } \\
\text { level tata } \\
\text { kelola } \\
\text { teknologi } \\
\text { informasi } \\
\text { dalam audit } \\
\text { keamanan } \\
\text { adalah 1,84 } \\
\text { berada pada } \\
\text { level } 2 \\
\text { (managed) } \\
\text { yang } \\
\text { bermakna } \\
\text { bahwa } \\
\text { proses } \\
\text { dijalankan. } \\
\text { Setelah } \\
\text { dilakukan } \\
\text { analisis } \\
\text { pada proses } \\
\text { APO13 dan } \\
\text { DSS05 }\end{array}$ \\
\hline
\end{tabular}

\begin{tabular}{|c|c|c|c|}
\hline $\begin{array}{l}\text { Nama } \\
\text { Peneliti }\end{array}$ & Judul & Masalah & $\begin{array}{c}\text { Hasil } \\
\text { Penelitian }\end{array}$ \\
\hline & & $\begin{array}{l}\text { untuk ke } \\
\text { depannya, } \\
\text { maka } \\
\text { diperlukannya } \\
\text { audit } \\
\text { keamanan } \\
\text { sistem } \\
\text { informasi. }\end{array}$ & $\begin{array}{l}\text { kapasitas } \\
\text { yang harus } \\
\text { dicapai } \\
\text { adalah ke } \\
\text { level } 5 \\
\text { sehingga } \\
\text { mampu } \\
\text { mencapai } \\
\text { tujuan } \\
\text { melalu } \\
\text { rekomenda } \\
\text { si jangka } \\
\text { pendek dan } \\
\text { jangka } \\
\text { panjang } \\
\text { dengan cara } \\
\text { menjalanka } \\
\text { n SOP dan } \\
\text { mekanisme } \\
\text { yang sudah } \\
\text { ada dalam } \\
\text { pelayanan } \\
\text { keamanan } \\
\text { di } \\
\text { perpustaka } \\
\text { an dan } \\
\text { melaksanak } \\
\text { an pelatihan } \\
\text { mengenai } \\
\text { keamanan } \\
\text { sistem dan } \\
\text { tugasnya. }\end{array}$ \\
\hline
\end{tabular}

\section{Metode Penelitian}

\subsection{Perencanaan (Planning)}

Perencanaan adalah tahap awal. Pada tahap ini melakukan studi literatur terhadap dokumen Universitas ARS Bandung yang berkaitan dengan Visi \& Misi, sasaran atau tujuan, rencana strategis, serta kebijakan-kebijakan yang terkait dengan pengelolaan investasi TI Universitas ARS Bandung. Pada tahap ini penelitian difokuskan pada Sistem Informasi Akademik yang ada di Univeritas ARS Bandung antara lain:

1) Aplikasi Sistem Informasi online (ars.ac.id). Merupakan sistem informasi seputar kampus baik kegiatan/aktivitas penerimaan mahasiswa baru, beasiswa mahasiswa baru, ataupun kegiatan kemahasiswaan lainnya.

1) Aplikasi absensi Mahasiswa \& Dosen. Merupakan sistem absensi perkuliahan mahasiswa serta data pertemuan perkuliahan dosen

2) Aplikasi KRS Online (mahasiswa.ars.ac.id) Merupakan sistem pengisian rencana studi, 
daftar nilai semester, rangkuman nilai, mahasiswa yang menggunakan jaringan internet online.

3) Aplikasi Sistem Informasi online (e-Learning). Merupakan sistem informasi tentang perkuliahan dengan nama e-learning.ars.ac.id. Sistem informasi digital dimana mahasiswa, mengupload tugas kuliah dan informasi kegiatan seputar akademik

4) Aplikasi Administrasi Keuangan. Merupakan sistem administrasi keuangan berupa data keuangan mahasiswa meliputi pembayaran perkuliahan dan kegiatan kampus lainnya

Sampai saat ini pengimplementasian aplikasi tersebut belum pernah di evaluasi, sehingga belum dapat memastikan keselarasan dengan tujuan bisnis TI institusi. Tata kelola teknologi informasi Universitas ARS Bandung dikelola oleh Bidang Administrasi Akademik dan Kemahasiswaan (BAAK)

\subsection{Pemeriksaan Lapangan (Fieldwork)}

Pendekatan ini bersifat pendekatan survey. Alat analisis yang digunakan dalam penelitian ini adalah dengan prosedur standar COBIT ( Control Objective for Information and Related Technology yang dikeluarkan oleh ISACA (Information systems Audit and Control Association).. Data yang digunakan dalam penelitian adalah data primer dan data sekunder yang diperoleh dengan metode kuesioner yang dirancang melalui COBIT Management Guidelines. Description of maturity level dapat digambarkan sebagai sekelompok pernyataan yang terstruktur di mana masingmasing deskripsi berisi pernyataan yang dapat bernilai sesuai atau tidak sesuai, dan sebagian sesuai atau sebagian tidak sesua. Data yang diperoleh dapat dengan berbagai metode yaitu :

a. Kuisioner, yaitu dengan cara

membagikan kuisioner kepada setiap bagian yang tergolong manajemen dan user. Adapun jumlah manajemen yang tersebar sejumlah 1 . Selain itu kuisioner yang disebarkan kepada user sejumlah 20 responden sesuai dengan teknik sampling purposive sumber datanya hanya pada mahasiswa yang pintar saja (IPK minimal 3,00) dan didapatkan 20 responden.

\subsection{Pelaporan (Reporting)}

Setelah kuisioner disebarkan, maka akan didapat data yang akan diproses untuk dihitung berdasarkan perhitungan maturity level. Untuk selanjutnya dilakukan beberapa tahapan dalam pelaporan, yaitu :

- Dilakukan analisis gap untuk melakukan analisa interprestasi hasil current maturity level dan expected.
- Rekomendasi berisi tindakan korektif mengatasi gap yang dilakukan untuk mendapai perbaikan yang dilakukan untuk institusi tersebut. Tindakan ini bagaimana menghasilkan nilai system infomrasi yang optimal.

- Bagaimana tindakan ini menghasilkan nilai sistem informasi yang optimal.

\subsection{Tindak Lanjut (Follow Up)}

Setelah melakukan pelaporan atau reporting maka hal yang dilakukan selanjutnya adalah memberikan laporan hasil audit berupa rekomendasi tindakan perbaikan kepada pihak managemen objek yang diteliti, untuk selanjutnya wewenang perbaikan menjadi tanggung jawab managemen objek yang diteliti apakah akan diterapkan atau hanya menjadi acuan untuk perbaikam dimasa yang akan datang (Jelvino; Andry, Johanes Fernandes;, 2017)

\subsection{Tahapan Metode Penelitian}

Dari ke-4 tahap dapat digambarkan dengan flow diagram sebagai berikut:

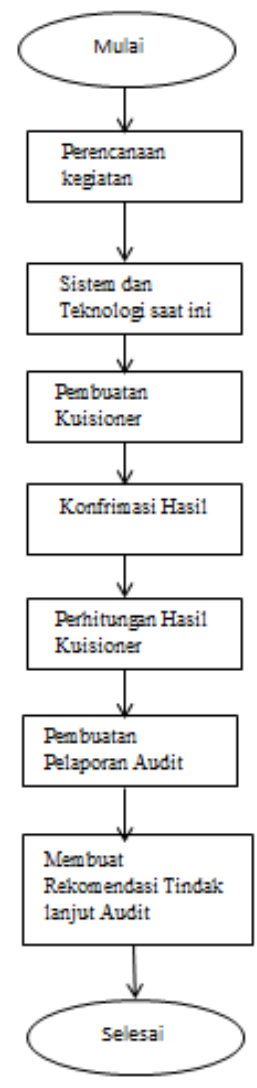

Gambar 3. Flowchart Penelitian

\section{Hasil Dan Pembahasan}

Sistem Informasi Akademik saat ini dapat dilihat dari hasil perhitungan tingkat kematangan (current maturity). Untuk mendapatkan nilai current 
maturity didapatkan dari index maturity $=($ jumlah jawaban kuisioner / jumlah soal control).

Pada BAAK dan Biro ICT-Center pada level user dan manajemen yang dapat dilihat pada tabel berikut:

Tabel 2. Tingkat kematangan (Maturity Level)

BAAK dan Biro ICT-Center untuk responden kategori user

\begin{tabular}{|c|c|c|}
\hline Domain & Proces & $\begin{array}{c}\text { Curent } \\
\text { Maturity }\end{array}$ \\
\hline PO2.1 & $\begin{array}{l}\text { Informasi } \\
\text { Arsitektur Model }\end{array}$ & 0 \\
\hline $\mathrm{PO} 2.2$ & $\begin{array}{l}\text { Peraturan Kamus } \\
\text { Data Perusahaan } \\
\text { dan Data Perintah }\end{array}$ & 0 \\
\hline $\mathrm{PO} 2.3$ & $\begin{array}{l}\text { Pengelolaan } \\
\text { Skema Klasifikasi } \\
\text { Data }\end{array}$ & 0 \\
\hline $\mathrm{PO} 2.4$ & Tingkat Keamanan & 0 \\
\hline PO7.2 & $\begin{array}{l}\text { Personil } \\
\text { Kualifikasi }\end{array}$ & 0 \\
\hline PO7.3 & $\begin{array}{l}\text { Peran dan } \\
\text { Tanggung Jawab }\end{array}$ & 0 \\
\hline PO7.7 & $\begin{array}{l}\text { Evaluasi Kinerja } \\
\text { Kerja Karyawan } \\
\end{array}$ & p \\
\hline PO8.1 & $\begin{array}{l}\text { Sistem manajemen } \\
\text { Mutu }\end{array}$ & 2,6 \\
\hline PO8.2 & $\begin{array}{l}\text { Standar IT dan } \\
\text { Praktik Kualitas }\end{array}$ & 4 \\
\hline PO8.3 & $\begin{array}{l}\text { Pengembangan } \\
\text { dan akuisisi } \\
\text { standar } \\
\end{array}$ & 2,5 \\
\hline PO8.4 & $\begin{array}{l}\text { Fokus pada } \\
\text { Pelanggan }\end{array}$ & 2,6 \\
\hline PO8.5 & $\begin{array}{l}\text { Kegiatan yang } \\
\text { berkelanjutan }\end{array}$ & 4,6 \\
\hline PO8.6 & $\begin{array}{l}\text { Pengukuran } \\
\text { kualitas, } \\
\text { pemantauan dan } \\
\text { review }\end{array}$ & 4,6 \\
\hline DS10.1 & $\begin{array}{l}\text { Permintaan } \\
\text { layanan dan } \\
\text { kebutuhan } \\
\text { informasi }\end{array}$ & $\beta, 3$ \\
\hline DS10.2 & $\begin{array}{l}\text { Kecenderungan } \\
\text { pengawasan dan } \\
\text { pelaporan }\end{array}$ & 2,5 \\
\hline DS11.1 & $\begin{array}{l}\text { Kebijakan dan } \\
\text { prosedur yang ada } \\
\text { untuk pengelolaan }\end{array}$ & 2,6 \\
\hline
\end{tabular}

\begin{tabular}{|c|l|l|}
\hline Domain & \multicolumn{1}{|c|}{ Proces } & Marent \\
\hline & $\begin{array}{l}\text { Maturity } \\
\text { data yang } \\
\text { didasarkan pada } \\
\text { kebutuhan bisnis }\end{array}$ & $\begin{array}{l}\text { Pertukaran dan } \\
\text { pengelolaan } \\
\text { penyimpanan data }\end{array}$ \\
\hline DS11.2 & $\begin{array}{l}\text { Peralatan dan } \\
\text { keamanan }\end{array}$ & 4,3 \\
\hline DS11.3 & $\begin{array}{l}\text { pembuangan data } \\
\text { yang tidak terpakai }\end{array}$ & $\begin{array}{l}\text { Data yang } \\
\text { mendukung dan } \\
\text { restorasi yang } \\
\text { teruji }\end{array}$ \\
\hline DS11.4 \\
\hline
\end{tabular}

Tabel 3. Maturity Level BAAK dan Biro ICT-

Center untuk responden kategori manajemen.

\begin{tabular}{|c|c|c|}
\hline Domain & Proces & $\begin{array}{c}\text { Curent } \\
\text { Maturity }\end{array}$ \\
\hline PO2.1 & $\begin{array}{l}\text { Informasi } \\
\text { Arsitektur Model }\end{array}$ & 4,7 \\
\hline PO2.2 & $\begin{array}{l}\text { Peraturan Kamus } \\
\text { Data Perusahaan } \\
\text { dan Data Perintah }\end{array}$ & 4 \\
\hline $\mathrm{PO} 2.3$ & $\begin{array}{l}\text { Pengelolaan } \\
\text { Skema Klasifikasi } \\
\text { Data }\end{array}$ & 4 \\
\hline PO2.4 & Tingkat Keamanan & 2,6 \\
\hline PO7.2 & $\begin{array}{l}\text { Personil } \\
\text { Kualifikasi }\end{array}$ & 4 \\
\hline PO7.3 & $\begin{array}{l}\text { Peran dan } \\
\text { Tanggung Jawab }\end{array}$ & 4,3 \\
\hline PO7.7 & $\begin{array}{l}\text { Evaluasi Kinerja } \\
\text { Kerja Karyawan }\end{array}$ & 4,3 \\
\hline PO8.1 & $\begin{array}{l}\text { Sistem manajemen } \\
\text { Mutu }\end{array}$ & 2,6 \\
\hline PO8.2 & $\begin{array}{l}\text { Standar IT dan } \\
\text { Praktik Kualitas }\end{array}$ & 4 \\
\hline PO8.3 & $\begin{array}{l}\text { Pengembangan } \\
\text { dan akuisisi } \\
\text { standar } \\
\end{array}$ & 4 \\
\hline PO8.4 & $\begin{array}{l}\text { Fokus pada } \\
\text { Pelanggan }\end{array}$ & 2,3 \\
\hline
\end{tabular}




\begin{tabular}{|c|c|c|}
\hline Domain & Proces & $\begin{array}{l}\text { Curent } \\
\text { Maturity }\end{array}$ \\
\hline PO8.5 & $\begin{array}{l}\text { Kegiatan yang } \\
\text { berkelanjutan }\end{array}$ & 2,6 \\
\hline PO8.6 & $\begin{array}{l}\text { Pengukuran } \\
\text { kualitas, } \\
\text { pemantauan dan } \\
\text { review }\end{array}$ & 4 \\
\hline DS10.1 & $\begin{array}{l}\text { Permintaan } \\
\text { layanan dan } \\
\text { kebutuhan } \\
\text { informasi }\end{array}$ & 4 \\
\hline DS10.2 & $\begin{array}{l}\text { Kecenderungan } \\
\text { pengawasan dan } \\
\text { pelaporan }\end{array}$ & 2,5 \\
\hline DS11.1 & $\begin{array}{l}\text { Kebijakan dan } \\
\text { prosedur yang ada } \\
\text { untuk pengelolaan } \\
\text { data yang } \\
\text { didasarkan pada } \\
\text { kebutuhan bisnis }\end{array}$ & 4 \\
\hline DS11.2 & $\begin{array}{l}\text { Pertukaran dan } \\
\text { pengelolaan } \\
\text { penyimpanan data }\end{array}$ & 2,3 \\
\hline DS11.3 & $\begin{array}{l}\text { Peralatan dan } \\
\text { keamanan } \\
\text { pembuangan data } \\
\text { yang tidak terpakai }\end{array}$ & 2,3 \\
\hline DS11.4 & $\begin{array}{l}\text { Data yang } \\
\text { mendukung dan } \\
\text { restorasi yang } \\
\text { teruji }\end{array}$ & 2,3 \\
\hline
\end{tabular}

Hasil perhitungan current maturity level untuk proses pada BAAK dan Biro ICT-Center, yang digambarkan dalam tabel Gap.

Tabel 4. Tabel Gap

\begin{tabular}{|l|l|l|l|}
\hline Domain & \multicolumn{1}{|c|}{ Proces } & $\begin{array}{c}\text { Curent } \\
\text { Maturi } \\
\text { ty } \\
\text { User }\end{array}$ & $\begin{array}{c}\text { Curent } \\
\text { Maturity } \\
\text { Manajemen }\end{array}$ \\
\hline PO2 & $\begin{array}{l}\text { Mendefinisi } \\
\text { kan } \\
\text { Arsitektur } \\
\text { Informasi }\end{array}$ & 3,8 & 3,8 \\
\hline PO7 & $\begin{array}{l}\text { Mengelola } \\
\text { Sumber } \\
\text { Daya } \\
\text { Manusia }\end{array}$ & 4,2 & 4,2 \\
\hline
\end{tabular}

\begin{tabular}{|l|l|l|l|}
\hline Domain & \multicolumn{1}{|c|}{ Proces } & $\begin{array}{c}\text { Curent } \\
\text { Maturi } \\
\text { ty } \\
\text { User }\end{array}$ & $\begin{array}{c}\text { Curent } \\
\text { Maturity } \\
\text { Manajemen }\end{array}$ \\
\hline PO8 & $\begin{array}{l}\text { Mengelola } \\
\text { Kualitas }\end{array}$ & 3,4 & 3.2 \\
\hline DS10 & $\begin{array}{l}\text { Mengelola } \\
\text { Permasalah }\end{array}$ & 2,9 & 3.25 \\
\hline DS11 & $\begin{array}{l}\text { Mengelola } \\
\text { Data }\end{array}$ & 3,45 & 2,7 \\
\hline
\end{tabular}

Tingkat kematangan saat ini (current maturity level) yang terendah dalam domain PO dan DS berada pada proses DS11 yaitu Memastikan Pengelolaan Data yang berkelanjutan kepada pengguna yang berada pada level 2,7. Sementara itu tingkat yang tertinggi berada pada proses $\mathrm{PO} 7$ yaitu Mengelola Sumber daya alam yang berada pada level 4,2 .

\section{Kesimpulan dan Saran}

4.1 Kesimpulan :

1. Dalam penelitian ini kami menggunakan domain PO dan DS.dalam domain tersebut berfokus pada sub domain PO2,PO7,PO8,DS10 dan DS11.Domain tersebut digunakan untuk acuan dalam kuesioner.

2. Gap yang ada antara rata-rata level saat ini dengan rekomendasi level menunjukkan gap yang besar, sehingga apa yang diharapkan dapat di penuhi dan dijalankan dengan baik oleh SIAKAD

3. Sistem SIAKAD yang saat ini diimplementasikan sudah sesuai dan mendukung tujuan sistem informasi akademik tersebut.

4. Dari hasil gap antar tingkat kematangan tata kelola TI saat ini dengan tingkat kematangan yang ingin dicapai, diketahui pada domain PO dan DS prioritas perbaikan dilakukan pada DS11 (memastikan pengelolaan data).

\subsection{Saran :}

Penelitian yang dilakukan tentunya tidak terlepas dari kekurangan dan kelemahan oleh karena itu, ada beberapa saran yang dapat diberikan untuk pengembangan lebih lanjut sebagai berikut :

1. Evaluasi tata kelola TI ini disarankan dapat dilakukan secara rutin setiap periode waktu tertentu (secara periodik), agar tingkat kematangan yang diinginkan dapat dicapai.

2. Dibuatkan suatu sistem yang dapat digunakan untuk proses tata kelola TI, mulai dari pengisian kuesioner sampai dengan proses pengolahan data.

3. Untuk kedepannya disarankan menggunakan framework COBIT versi terbaru agar tata kelola 
TI mendapatkan hasil evaluasi lebih lengkap dan lebih mendalami dalam audit SIAKAD.

4. Untuk kedepannya memastikan pengelolaan data pada DS11 lebih di tingkatkan agar sistem SIAKAD lebih baik kedepannya.

\section{Daftar Pustaka:}

Admin. (2019, Februari 15). Apa itu tata kelola IT. Diambil kembali dari Tata KelolaIT: https://netsolution.co.id/apa-itu-tata-kelolati-atau-it-governance/

Jagad. (2019, januari 20). jagad.id. Diambil kembali dari pengertian sample: https://jagad.id/

Jelvino; Andry, Johanes Fernandes;. (2017). Audit Sistem Informasi Absensi pada PT. Bank Central Asia Tbk menggunakan COBIT 4.1. Jurnal Teknik Informatika dan Sistem Informasi Volume 3 Nomor 2 Agustus 2017, 3.

Prihandoyo, m teguh. (2018). Unified Modeling Language (UML) Model Untuk Pengembangan

Sistem Informasi Akademik Berbasis Web. Jurnal Informatika: Jurnal Pengembangan IT, 3(1), 126-129.

Rizki. (2019, april 9). teknik analisi data . Diambil kembali dari analisi data: https://pastiguna.com/

Salamadian. (2017, februari 12). teknik pengambilan sampel. Diambil kembali dari pengambilan sampel: https://salamadian.com/

Suhartono, B. (2016, Mei 22). Tata Kelola IT dengan menggunakan Frame Work COBIT. Diambil kembali dari bambangsuhartono.wordpress.com: https://bambangsuhartono.wordpress.com/2 016/05/22/tata-kelola-it-denganmenggunakan-frame-work-cobit/

Sulaeman, F. S. (2015). Audit Sistem Informasi Framework Cobit 5 Data Nasabah PT . AF per tahun. Media Jurnal Informatika, 7(2), 37-42. https://scholar.googleusercontent.com/scholar? q=cache:LrgXITLUh-

0J:scholar.google.com/+audit+sistem+informa si+dengan+cobit\&hl=id\&as_sdt $=0,5$ 
Volume 6, Edisi 3, Mei 2020

$64 \mid \mathrm{H}$ a 1 a $\mathrm{m}$ a $\mathrm{n}$ 